\title{
Analysis of Green IT Features for Improving Business Performance
}

\author{
Srikanth Subburaj, Siddhivinayak Kulkarni \\ School of Science, Information Technology and Engineering \\ Federation University, P. O. Box 663, VIC-3353, Asutralia
}

\begin{abstract}
Nowadays business growth vastly depends on computing resources but its environmental cause and effect relating to its footprints are closely monitored by regulatory bodies. To achieve business goals, data centres anticipate growth and its computing resources consume high energy that results to carbon footprints. Green IT plays an important role to address these issues by offering various Green IT initiatives through which efficiencies are met to reduce the footprints. Representation of a Green IT initiative with its business benefits gives organizations an immediate boost to choose initiatives that yields values as per their business model. This research aims to develop an EPL model considering three Green IT initiatives Energy [E], Policy $[P]$ and Legacy $[P]$ and reveals its business benefits.
\end{abstract}

\section{Introduction}

It is evident that under current economic situations businesses are under pressure and exploring ways to do more with less by applying efficiencies in all their operations. With the increasing energy costs and compliance requirements, vendors take serious measures during product development to achieve high Energy Star (Authenticates equipment's Energy-Efficiency levels) to meet compliance and consumers requirements. Information and Communication Technology (ICT) plays a significant role in offering such innovative solutions to achieve businesses' expected efficiency operations requirements, so implementing green technology is rising to top of every organization's agenda.

There are numerous Green IT initiatives which facilitate businesses to perform in a low-carbon economy. In 2010, Europen Comission's Green IT strategy for a sustainable Europe [16] defines the role for ICT, and its significance in Energy Management ("Smart Metering" by which consumers manage their energy consumption), Building \& Construction (ICT solutions to improve the environmental and energy performance of new and existing buildings) and Transports and logistics (ICT potentials to improve the environmental and energy performance of Transports and logistics services). Businesses that underutilize their assets (equipment, building etc.) leads to a costly business problem, to avoid such problems it has to adopt efficiency in areas of business operations like energy utilization, material reusability and extension of materials useful lives. A Green IT policy which is aligned with business strategic would help organizations to bring such material efficiency and saves money and also helps organizations to reduce their carbon footprint.

Leading organization has demonstrated return on investment by adopting Green IT approaches like efficient energy management and "green computing" policies. Organizations implement solutions that offer greatest return in energy-efficiency considering their cost, technical feasibility and management support. As per the reality check by CDW [5] reveals the businesses perceptions of struggle in implementing energy efficient solutions to be greater than those who have technically implemented them in reality. For example, Lucas Films estimated 3 million $\mathrm{kWh}$ energy savings by selectively investing in energy-efficient equipments and software. It is evident that the Green IT initiatives make sound economic sense and also provides substantial savings.

As there are several Green IT features which could address the environmental problem but it should be selected based on [selecting them should be based on] the strategic decision of an enterprise there are tools and methodology for selecting a green technology portfolio from an environmental strategic perspective, the objective of which is to maximize the economic benefits and environmental benefits of an enterprise (International journal 2010). This EPL model analyzes there features and provides its business benefits by which organization can choose their Green IT features based on their objectives.

This paper addresses three major factors: Energy, Policy and Legacy systems their relations to achieve improved business performance. The rest of this research broadens its view into following topics: Section 2 - describes Related Work. Section 3 - E-PL Model with their relationships; Section 4 Analysis and Discussion; Section 5 - Conclusion.

\section{Related Work}

Organizations have widely accepted to adopt IT for better efficiency and streamlining production. 
According to analysis the Enterprise Resource Planning (ERP) adoption in India's Small and Medium enterprise (SME) found that implementing ERP was helpful to improve the performance of the company in planning operations, improved productivity and to structure the business process. Moreover, it also identified Green IT factors (Supply chain, Compliance, Efficiency, Energy and Asses Management etc.) that have strongly influenced EPR phases (Planning, Acquisition, Implementation, Usage and Production Extension) and enhanced the business process efficiency in organizations [4]. The managers is pressurized to deliver more with less budget, it can be achieved by enterprise Green IT initiatives like material efficiency, energy efficiency etc. CDW's Energy Efficient IT reports $90 \%$ of organizations pursuing Green IT initiatives reported favorable results and $39 \%$ cuts energy cost by $1 \%$ [6].

\subsection{Energy Feature}

ICT emissions are increasing at a rate $6 \%$ per year; with this growth rate they could represent $12 \%$ of worldwide emissions by 2020 [13]. To achieve business goals, data centres anticipate growth and it consumes high energy. Example:- an increase in processor speed at the rate of twice the speed of it would quadruples the power consumption so it is important to monitor energy requirement of data centers and its associated costs which facilitates its management with accuracy. The Data Centre energy consumption can be managed efficiently and accurately by adopting green Energy monitoring metrics like Power Usage Efficiency [PUE] to measure individual components for performance and efficiency. If the energy is monitored and managed at components level (data switches, network, storage etc.), it provides a way to makes data centres more efficient to handle energy issues to minimize carbon footprint. Energy efficiency can also be achieved at data centres by avoiding multiple conversions between alternating current (AC) and direct current (DC) [17]. Earlier data centers resource was highly optimized to provide high performance for business operation until Green IT energy monitoring metrics were introduced, technologies like virtualization, cloud computing solutions and building data centers at abundance renewable energy sources (water, solar etc.) have emerged due to energy efficiency requirements. Carbon Trust reports office equipment's consumes $15 \%$ of the total electricity used in office and it's likely to increase to $30 \%$ by 2030 [2].

With energy efficiency techniques energy consumption can be reduced. Power efficiency can be acquired with different techniques: - efficient cooling to address heat issues, power management software solutions to run PC's with optimal power, hardware solutions such as multi-core microprocessor design and energy proportional hardware designs that reduces power usage of memory and disk-subsystems [20]. Moreover, reducing energy consumption requires Planning and Operational improvements.

Planning improvements requirements are:

- Infrastructure design should include solution like virtualization, cloud computing and building data centers at abundance renewable energy sources.

- Strategic energy efficient techniques that are used in data center should be aligned with its Green IT policy, which allows energy to be monitored and managed at components level.

- Allows data centres to cope up with ever-growing business demands.

- Analyze system performance requirements as per the business needs and its energy consumption requirements, over provisioning system for performance will quadruple the power requirements.

Operational improvements requirements are:-

- Power Usage Efficiency (PUE), which only indicates ratio of infrastructure to IT power consumption but it, does not provide information on efficiency of equipment and consumption. A significant amount of accurate sub-metering or shared load allocation is necessary to obtain the required information. However, it was used to compare dissimilar data centres efficiency between organizations, which brought ambiguities.

- An elementary framework and techniques to measure power consumption and efficiency is still in evolution stage in market.

- There is no industry standard metrics to calculate energy and carbon footprints.

- Server consolidation through which underutilized server resources can be consolidated for energy efficiency which saves energy and cost and at the same time reduces the emission of greenhouse gases.

It is advised to consolidate servers based on the workload those servers perform e.g.: Innovation Servers, Production servers and mission critical servers rather than allocating it for each business unit but it will vary depending on organizations infrastructure [21].

\subsection{Policy Feature}

Organizations to pursue the Green IT a well understanding of Green IT readiness of the organization is required, for evaluating its Green IT readiness; IT should have the governance to assess and facilitate the implementation of Green IT policies and strategies in an organization [8]. 
Implementing Green IT factors without strategy will remain only for economic reasons and provides short term benefits. It will certainly not meet financial expectations and long term sustainability. As varieties of risks affects Green IT practice at four stages :- (awareness, translation, comprehension and Green IT values) the Green IT as a policy for environmental sustainability is a must, through this industries can sustain carbon emission targets set by carbon regulatory bodies [7]. Green IT policies strategies' decisions happening at boardroom level which integrates sustainability objectives across the entire operations using IT-enabled business processes.

The overall Green IT maturity level is low across all industries in all countries and it is due to lack of Green IT policies and practices. As per the survey (ICT Digital Literacy) the Green IT maturity level index for United Kingdom is 61.0 and The USA is 58.6 followed by Australia 53.9 - due to low level of measurement factors and India (52.0) due to lack of end user Green IT implementation. As a Green IT policy, integrating green key performance indicators into business-as-usual becomes strategic and meets overall sustainability objectives of the industries. The barriers in implementing Green IT as a policy are cost consideration, lack of managerial awareness, and the legacy IT infrastructure. A comprehensive cost model and the awareness programs stressing the relevant benefits can translate Green IT initiative into policy [12] and it links technologies with organizational practices to address acknowledged business problems.

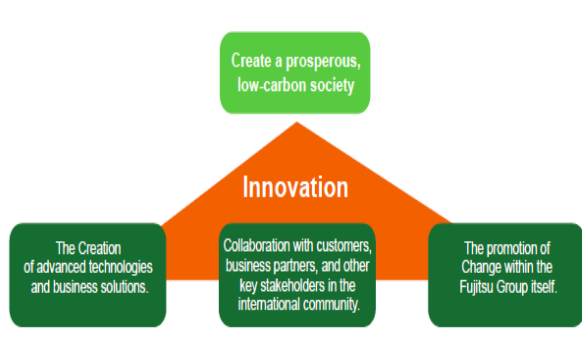

Figure 1. Policy Features low-carbon outcome (Source: Case Study Fujitsu - Journey Over Time)

Organization that strives business decision by considering environmental protection as a corporate value have used Green IT policies and transformed its business processes to gain efficiency and for a long-term sustainability. To change business processes organizations have widely used Policies Example: Fujitsu established a sustainable business unit in Australia which is responsible for driving global initiatives locally, its 'Green Policy 2020' which aimed to reduce $\mathrm{CO} 2$ emissions by 30 million tons by 2020 through environmental innovation. Fig 1.0: shows its Green Policy is embodied by the three keywords: Creation, Collaboration, and Change.
With these policy approach achieved the reductions of 60,000 tons of $\mathrm{CO} 2$ emissions were projected from the provision of Green Policy Platform (IT Infrastructure - Server, Network Products etc), and a further 680,00 tons from Green Policy Solutions (IT Solutions - Outsourcing, Consulting).

\subsection{Legacy Feature}

Legacy systems expend $75 \%$ of IT maintenance budget due to challenges like unavailability of skilled personnel, hardware and software obsolescence and this is addressed by exposing legacy systems to Service-Oriented Architecture (SOA). The feasibility of exposing legacy system functionality as services within an SOA environment for an organization can be validated by Service Migration and Reuse Technique (SMART) processes [1]. The maintenance cost of legacy system would be between $40 \%$ and $90 \%$ of the total costs of the life cycle of the system [23]. Migrating the legacy systems to modernized and flexible technologies will yield Reduced TCO (Total Cost Of Ownership), minimizes risk by moving off costly and outdated resources and adds value by maximizing the resource utilization of the infrastructure whereby energy efficiency is achieved. Legacy application that are retrofitted to work with modern business infrastructures, companies found that those applications costing them disproportionate amounts of their IT budgets. Most of the study shows legacy modernization effort may fail without meeting its business objectives due to its complexity, technology and resource availability. An organization that takes serious measures to meet energy efficiency criteria and budget requirements requires a predefined Green IT policy for sustainability which should link such requirements.

Retiring Legacy systems also brings energy efficiency but to measure the power consumption by legacy software systems is a challenge. However, hardware utilized by those systems leads to indirect energy consumption. Upgrading such systems to engineered software with optimized energy consumption in mind brings energy efficiency and it is mandatory for the sustainable environment. Retiring Legacy systems should be carefully addressed due to the following reasons:-

- Legacy systems that are modernized creates a conflicts in respect to end-users' requirement and service quality until a certain brief period.

- Sometimes data rich strategic legacy systems can be modernized with respect its user friendliness' and business priorities but without considering its efficiency with respect to environment.

- Moving legacy systems to modern and open technologies is a challenge due to outdated technology and diminishing pool of technicians 
to support legacy systems and lack of system documentation.

"Greening Legacy system" which addresses how legacy systems can be ported into a software systems which plays proactive role in energy savings and results in environmentally friendly software.

\section{E-P-L Model with their relationship}

This section details the impact rates of Energy, Policy and Legacy Green IT initiates in organizations to improve business performance. Environmental and economical benefits are the strongest factors of these three Green IT initiatives.

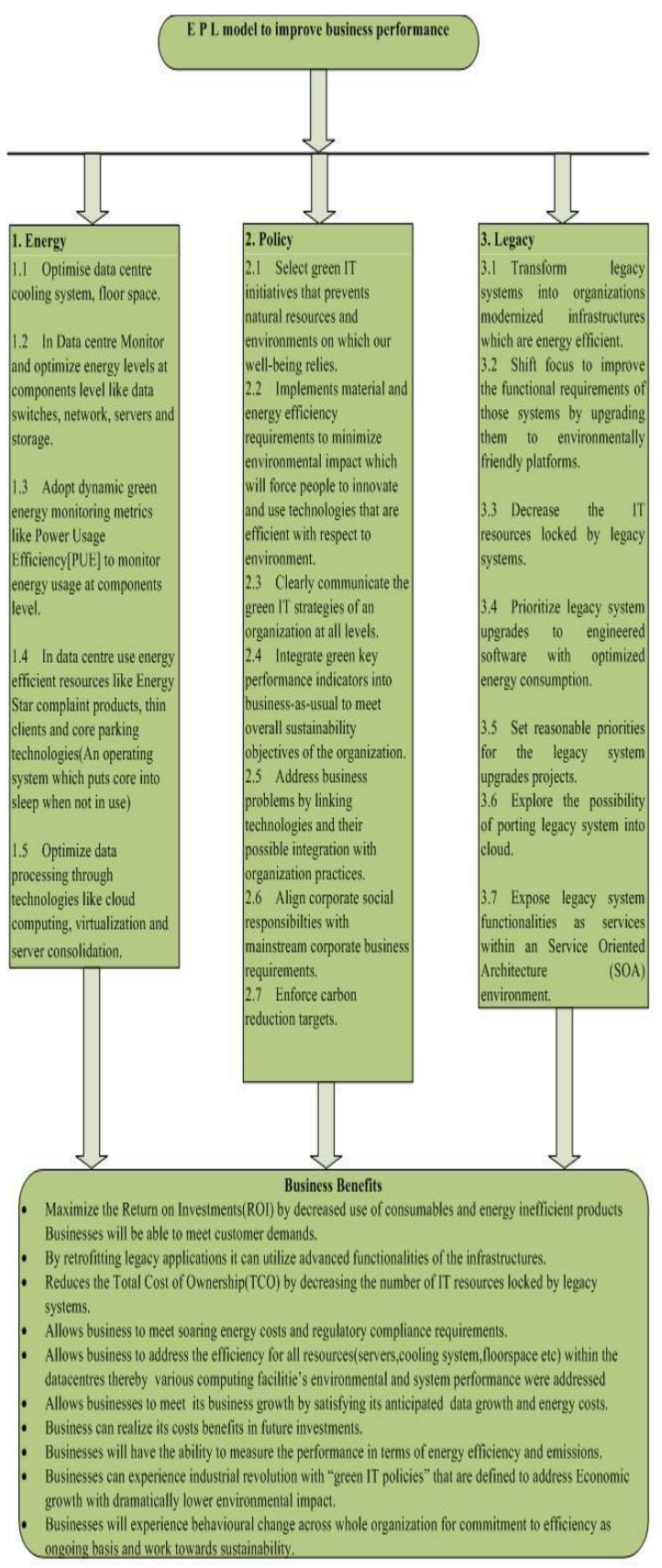

Figure 2. E-P-L model for business
With Energy initiatives the major economic benefits are decreased electricity use, decreased consumables use. With Policy initiatives the legislation requirements for environmental can be met. Moreover, it also guides rest of the Green IT initiatives to meet the targeted benefits set by businesses. With legacy initiatives the major economic benefits is decreased future operational expenses and able to run systems in more energy efficient resources with advanced technical infrastructures.

The strong business case for many businesses to implement Green IT initiatives is the rising energy and operational cost but when choosing a Green IT initiatives there are concerns for the environment against business improvements and cost benefits. Companies vary in selecting and implementing Green IT initiatives, based on their own operations and their ability business benefits can be realized. Indeed, a well defined Green IT policy plays an important role in determining the purpose of Green IT initiatives in place and methods to achieve it. With current economic condition businesses are interested in investment if they have a solid Return On Investment (ROI) and business benefits. However, selecting an appropriate Green IT initiatives raises challenges and opportunities but it can also be stream lined once the business benefits are realized. This study has developed an E-P-L model as shown in Figure 2: to list business benefits that can be achieved from the three Green IT initiatives Energy, Policy and Legacy.

\section{Analysis and Discussion}

Organization's that took environmental issues as a business and opportunity challenge has succeeded. Even smaller companies also benefit from going to green based on "how smart use environmental strategy to innovate, create value and build competitive advantage" [9]. With this EPL model, by selecting initiatives as per their environmental effort from any of those categories business's can alleviate environmental risks, operational costs and attain benefits.

\subsection{Analysis of Energy Issue}

ICT emissions are increasing at a rate $6 \%$ per year, with this growth rate they could represent $12 \%$ of worldwide emissions by 2020 [13]. At data center these issues could be addressed as per the EPL's 1.2, the energy should be monitored at components levels like data switches, network and server etc. this flexible and dynamic energy monitoring methods handles energy issues and reduces carbon foot print. 
EPL 1.1 suggests optimizing data centre's cooling system allows business to meet soaring energy costs. The Thermal-efficient resource management shows that software driven thermal management and temperature aware workload placement brings additional energy savings but it is not fully utilized in virtualized data centres [3].

EPL 1.4 suggests use energy efficient resources like Energy Star compliant products, thin clients etc. all these techniques provides substantial energy savings. According to IDC the energy cost to power the servers will exceed the cost of server by next year, so energy monitoring is vital for developing energy efficient resources like core parking techniques which is adopted in operating systems which puts core into sleep when not in use, thin client (Sun Ray ultra-thin client) which consumes just $4 \mathrm{~W}$ instead of a PC that consumes $70 \mathrm{~W}$ and a software base solutions citrix, VMware etc.

With EPL 1.5, in data centres energy can be optimized through technologies like virtualization and cloud computing which promotes energy efficiency and minimizes environmental impact thereby organizations can meet compliance requirements. The Microsoft research found that moving applications to cloud will cut the per user carbon footprint by $30 \%$. According to a Pike research the cloud computing cloud lead to a $38 \%$ reduction in world-wide data centre energy usage by 2020.

\subsection{Analysis of Policy Issue}

Implementing Green IT practice requires commitments from everyone to follow environmental regulations at their work and homes. When it is aligned as a policy it delivers change of behaviors across whole organization and brings commitments. It is believed that next wave of economy growth will be driven by information technologies but if combined with material and energy efficient technologies during manufacturing it has the potential to create an economy with dramatically lower environmental impact [11], "Green IT policies" that are defined should have such industrial revolution.

EPL 2.1 suggests "Select Green IT Initiative That Prevents Natural Resources, by implementing the selected Green IT initiatives through an established organization level Green IT Policy for environment provides opportunities to prevent natural resources and environments on which our well-being relies.

EPL 2.2 suggests "Implement Material Efficiency":- with a Green IT Policy, the Green IT strategies of an organization can be clearly communicated at all levels, if material and energy efficiency are included within to minimize environmental impact which will force people to innovate and use technologies that are efficient with respect to environment.

EPL 2.3 suggest "Clearly Communicate the Green IT strategy" for example if "Energy Efficiency" has been set as a part of Green IT Policy, substantial improvements can be achieved on these areas: -

- Replacing old equipments [Server, Desktops and Network Devices etc.] with energy efficient equipments. [E.g.:- 1. Modern desktop consumes around 25 per cent of the power than its predecessor. 2. Modern server consumes approximately 20 per cent less energy than its predecessor]

- Improved Data Centre designs like virtualization of IT resources and adopting efficient cooling of IT resources by placing equipment is such a way that less cooling is required.

- Dynamically allocate resources servers, storage and bandwidths as per the requirements where by resource utilization can be increased to 70 to 80 $\%$ so that targeted Power Usage Efficiency (PUE) can be achieved.

EPL 2.7 "Enforce Carbon Emission Targets":- the Green IT Policy with Carbon Emission Targets contributes towards reducing carbon emissions across the organization by the following ways:-

- It defines measurement methods by which energy consumption and carbon emissions will be measured.

- It enables to set targets and provides methods to reduce ongoing carbon emission.

\subsection{Analysis of Legacy Issue}

In many organizations, Legacy systems are built with enriched historical information to support its businesses effectively in a competitive market. Generally, such IT systems are built by addressing the specific business needs of an organization. As these IT systems used over a period of years and proven its significance for running a success business, organizations tended to invest further on these systems. The main reasons for organizations to keep legacy systems over enterprise resource planning (EPR) systems was that "Existing Systems Works" and "Other Project Priorities [15] this prevents legacy systems to be modernized for environmental purpose and use flexible technologies. As per the NASCIO survey in 2008, in the States the modernization of legacy systems with respect to Green IT initiatives' is $28 \%$. Legacy modernization requires trade-offs and it's multifaceted, which includes technical and organization considerations that may affect organization decision-making abilities [22]. A Green IT investment project addressing those risks will provide options to retrofit legacy systems in green Data Centres. 
EPL 3.1 suggests "Transform Legacy System into Organizations Modernized Infrastructure", the new IT resources has the ability to turn off processors and entire computers according to demand without hindering IT services as these capabilities also offered via a software update, legacy equipment can also benefit from these techniques [18].

EPL 3.2 suggests "Move legacy systems to modernized infrastructure" so that focus can be shifted to functional improvements of legacy systems instead of maintaining old energy inefficient resources at data centers just for legacy systems.

As per EPL 3.3 "Decrease IT resources locked by" legacy systems consume more IT resources and its emissions will have a negative impact on the environment. Decreasing the IT resources locked by legacy systems also leads to decreased maintenance expenses and total cost of ownership (TCO) otherwise with an increase in energy cost they will become dearer to maintain.

As per EPL 3.4 "Prioritize Legacy Systems Upgrade" Measuring the power consumption by software like legacy systems is challenging, but hardware utilized for those systems leads to indirect energy consumption. However, upgrading legacy systems to engineered software with optimized energy consumption given priority results in less energy consumption and a sustainable environment.

As per EPL 3.5 "Set reasonable priorities for legacy system upgrade" Survey of National Association of State Chief Information Officers for prioritize technologies and application ranking shows Legacy application modernization falls in rank 6 [19]. Within category of improving State (Texas) Operations the Statewide rollout project TIERS (Texas integrated Eligibility Redesign System) estimated to bring $\$ 30$ million annually for retiring the legacy system, this was a joint effort between policy, operation and technologies. It shows policy and technologies upgrade plays an important role in bringing business benefits.

\section{Conclusion}

Many organizations have realized environmental and economic benefit options must be adopted in their operations for sustainability, which encourages them to implement Green IT factors to reduce emissions in a serene way. Moreover, they are continuously monitoring their business operations for efficiency and adopting changes to reduce both capital and operational cost. This paper analyzed three Green IT factors (Energy, Policy and Legacy) derived an E-P-L model which list actions performed and correlates its output as business benefits. In addition to this, in analysis section it authenticates each of its model items and its associated environmental and economic benefits that businesses have realized.
This E-P-L model provides a simple view by which any business decides to implement the listed Green IT initiatives within each category (E-P-L), it allows them to visualize its deliverable business benefits easily. This model also illustrates how these three E-P-L Green IT initiatives are interlinked and the business benefits it yields.

\section{References}

[1] Balasubramaniam, S., Lewis, G.A., Morris, Ed., Simanta, S., and Smith, D. (2008) "SMART: Application of a method for migration of legacy systems to SOA environments", in Service-Oriented Computing - ICSOC 2008, 6th International Conference, Sydney, Australia, December, Eds., vol. 5364, 2008, pp. 678-690.

[2] BCS The Charted Institute for IT (2012). 'Green IT: Managing your carbon footprint'. BCS, The Charted Institute for IT. 68.

[3] Beloglazov, A., Abawajy, J. and Buyya, R. (2012) 'Energy-aware resource allocation heuristics for efficiency management of data centers for cloud computing'. Future Generation Computer Systems, 28(2012). 755-768.

[4] Bharathi, S., Raman, R. and Pramod, D. (2013) 'A principal component analysis to identify the Green IT factors that impact ERP adoption in India small and medium enterprises', European Journal of social sciences, issn 1450-2267, Vol. 37, pp 559-582.

[5] CDW (2009) 'Implementing Green IT Eleven ways I.T. can lower power consumption, reduce costs \& eliminate waste'. [Online] Available from http://www.techrepublic.com/resource-

library/whitepapers/implementing-green-i-t-eleven-ways-it-can-lower-power-consumption-reduce-costs-eliminatewaste/\#. (Accessed 25 Feb 2014)

[6] CDW 2012 'Energy Efficient IT Report'. [Online] Available from

http://webobjects.cdw.com/webobjects/media/pdf/CDW_E nergy_Efficient_IT_040212_FINAL.pdf (Accessed 17 Jun 2013)

[7] Chou, D.C. (2013) 'Risk Identification in Green IT Practice'. Computer Standards \& Interfaces, 35(2013). 231-237.

[8] Deng, H., Molla, A. and Corbitt, B. (2009) 'A fuzzy logic based green information technology readiness model', AICI '09. International conference, Vol1, pp 465470 .

[9] Esty, Daniel C. and Simmons, P.J. (2011) How to Implement Sustainability Practices for Bottom-Line Results in Every Business Function [online]. Universitv Of Ballarat. Australia VIC. 470-475[Accessed 04 Oct 2013].

[10] Fujitsu-Green Policy Innovation (2011) Report. [Online] Available from: http://www.fujitsu.com/downloads/ECO/rep2011/fujitsu20 11report-e.pdf (Accessed 20 Feb 2014). 
[11] Perez, Carlota. 2010. "Technological Revolutions and Techno-Economic Paradigms." Cambridge Journal of Economics, Volume 34: 185-202.

[12] Sarkar, P. and Young, L. (2009) 'Managerial attitudes towards Green IT: an explorative study of policy drivers', Pacific Asia Conference on Information Systems [online] Available from: accessed http://aisel.aisnet.org/pacis2009/95

[13] The Climate Change Group Smart 2010: Enabling the Low Carbon Economy in the Information Age. [Online] www.smart2020.org/_assets/files/03_Smart2020Report_lo _res.pdf (Accessed 17 August 2011).

$\begin{array}{rrrr}\text { [14] ICT Digital Literacy } & \text { Green } & \text { IT: The Global } \\ \text { Benchmark } & \text { Accessed } & \text { on } & \text { [online] }\end{array}$ http://www.ictliteracy.info/rf.pdf/green_IT_global_bench mark.pdf (Accessed on 20-Mar-2013).

[15] Kaplan, J., Forrest W., and Kindler, N. 'Revolutionizing Data Centre Energy Efficiency', McKinsey \& Company, tech,Rep., Lightfoot, E. and Salaway, G. (2003) 'A Different Kind of ERP Extending and Renewing Legacy Systems', ECAR Research Study, Volume 2003, Issue 5.

[16] Maloney, C. (2010) Green IT Strategies and Practices for a Sustainable Europe. [Online] Available from http://ec.europa.eu/information_society/activities/sustainab le_growth/docs/events/past_events/cebit.pdf (Accessed 11 Jun 2013).

[17] McKenna P (2008) Can we stop the internet from destroying our planet? New Scientist 2008, January.

[18] Mohammad, O., Alagan, A., and Isaac, T. (2012) Handbook of Green Information and Communication Systems [online]. Universitv Of Ballarat. Australia VIC. Available from: http://innopac.ballarat.edu.au/ Pages 470475[Accessed 12 Mar 2013].

[19] NASCIO 2014, State CIO Priorities for 2014 [online]. http://www.nascio.org/publications/documents/NASCIO_S tateCIOTop10For2014.pdf [Accessed 10 Nov 2013].

[20] Paleologo G, Benini L, Bogliolo A, De Micheli G. Policy optimization for dynamic power management. In proceedings of design automation conference. 1998 June p.182-7

[21] Uddin M., and Rahman A (2012) 'Energy Efficiency and low carbon enabler Green IT framework for data centres considering green metrics'. Renewable and Sustainable Energy Reviews 16 (2012) 4078-4094

[22] Robert, C S., Plakosh, D. and Lewis G.A. 2003. Modernizing Legacy Systems: Software Technologies, Engineering Processes and Business Practices. Carnegie Mellon. The SEI series in Software Engineering, Pearson Education Inc. Boston MA.

[23] Saarelainen, M. M., Ahonen, J.J., Lintinen, H., Koskinen, J., Kankaanpaa, I., Sivula, H., Juutilainen, P., and Tilus, T. 2006. Software Modernization and Replacement Decision Making in Industry: A Qualitative
Study, Evaluation and Assessment in Software Engineering. 